\title{
Community well-being and the 'invisible' subjectivities of indigenous people: a focus on the Irulas of the Nilgiri Biosphere Reserve, Tamil Nadu, India
}

\author{
Jyotsna Krishnakumar* and Pratim Roy
}

Barring a few advantages, human development index renders subjective characteristics experiences, and requirements of indigenous communities rather mute. In this article, we aim to highlight the relevance of community well-being as an appropriate tool to measure 'development' and highlight the nuances specific to indigenous communities, focusing on the Irulas of the Nilgiri Biosphere Reserve in Tamil Nadu. Overall, we found that individual well-being is an outcome of collective well-being, wherein social cohesiveness, traditional practices and cultural identity, all become paramount. These findings also align with the goals of progressive missions like the National Mission on Biodiversity and Human Wellbeing, pertinent in terms of reconciling the erstwhile disregard for development initiatives to indigenous concerns.

Keywords: Cultural identity, governance, indigenous communities, livelihoods, well-being.

ACCORDING to Krishnan ${ }^{1}$, ‘... India has one of the largest ecological footprints in the world, and unprecedented changes in social, economic, and environmental-systems ... are threatening its biodiversity'. As moving and alarming such statements may seem, the actual condition of the quality of life seems to be defined by human development index (HDI), which undermines this inter-connectedness.

Out of 189 countries in the world, India was ranked 130 (with a HDI score of 0.64) in 2018 (ref. 2). Although these objective calculations help us gauge the country's performance at a global level, they do not, inform us on subjective experiences. And yet, these indices influence the 'interventions' aimed at 'uplifting' the marginalized. What this does, in turn, is to reduce 'beneficiaries' to passive recipients and mere data.

Over the last few decades, the goal has been to make the HDI framework more inclusive and people-oriented. Further, Krishnan ${ }^{1}$ draws attention to the failure of the Indian state to take into account the role of biodiversity sciences to (measuring) human well-being. In this regard, the state of well-being of indigenous communities and their association with the forest-landscape becomes relevant.

Haq et $a l .^{3}$ have been advocating for inclusion of the 'social' factors as important indicators to measuring well-

The authors are in the Keystone Foundation, PB 35, Groves Hill Road, Kotagiri 643 217, India.

*For correspondence. (e-mail: jyotsna@keystone-foundation.org) being of an individual. The capabilities approach, offers a new dimension to measuring 'improvement' in human conditions by way of capturing an individual's ability to access and utilize resources. However, the inability of HDI to capture 'improvement' in a holistic sense renders it a redundant measure of well-being, leaving the 'invisible' subjectivities of the indigenous being untapped. It becomes pertinent, therefore, to view the concept of well-being from the perspective of livelihood outcomes, political autonomy, and its implications for traditional knowledge systems and cultural practices, and consequences for mental and physical health, ubiquitous to the indigenous reality.

Community well-being (CWB) as a concept has been used synonymously with 'quality of life' and 'wellness'. It is achieved when the economic, social, physical, psychological, political and cultural conditions of individuals within a community are satisfied.

Reducing vulnerabilities and increasing resilience become a priority when considering the well-being of indigenous communities. Similar to the capabilities approach proposed by $\mathrm{Sen}^{4}$, the emphasis is on non-material factors and the capacity to decide and function, and not on maximizing utility/income alone.

There are subjective and objective approaches for measuring well-being. The subjective approach focuses on satisfaction, motivations and capacities, while the objective approach focuses on empirically observable material conditions such as life-expectancy, income, education, 
democratic participation, and social and land security (similar to the HDI indicators). In the indigenous context, CWB should be measured by combining the subjective and objective conditions identified by the communities as essential for them to flourish and fulfil their potential ${ }^{5}$.

\section{Community well-being and indigenous communities}

When examining CWB in the context of indigenous people, besides their socio-economic status, health and wellness, and political capacity or democratic participation, other components are also considered. For instance, many Inuits are still heavily involved in traditional economic pursuits, which, although contributing to their material well-being, are not manifested directly into monetary terms/paid employment. This suggests that perhaps there is a quality of intangibility to life satisfaction that Inuits derive from their traditional economic pursuits ${ }^{6}$.

Moreover, traditional and cultural linkages, identity, connection with nature and/or the spiritual world also become relevant ${ }^{7}$, and there are multiple ways to measure them $^{8}$. One example is the use of traditional language as a proxy to measure traditional linkage ${ }^{8}$.

Cultural well-being that comprises elements such as cultural composition of communities (e.g. where there is integration of indigenous cultural/ethnic groups and other mainstream communities); perceptions around ethnic/cultural identity; around isolation (e.g. limited or no contact with the mainstream), and size/population of the communities are all key indicators while assessing the well-being of indigenous communities ",

Contextualization of well-being outcomes, beyond the conventional measures, is also important when assessing CWB among indigenous communities ${ }^{10}$. For example, to understand the strength of cultural linkage, language or isolation may not be relevant in the context of the indigenous communities residing in the Nilgiri Biosphere Reserve (NBR), Tamil Nadu, India. On the other hand, community size, perceptions around identity, community composition are all contextually relevant factors, often shaped by livelihood profiles, demographic changes, migration to and from communities, economic development, etc. which over time may affect well-being either positively or negatively. In addition, physical and mental health, land and social security are key social and political factors that can affect well-being. Indigenous communities in India, also referred to as scheduled tribes (STs) comprising $9 \%$ of the total population, have always had a challenging history and continue to experience marginalization. As previously mentioned, HDI does not provide a holistic status of 'development' or well-being; neither does it capture conditions specific to communities who occupy special category status compared to general population. Unfortunately, an indifference to the subjective realities of indigenous communities in India has not allowed for a well-being perspective to thrive. In this regard, our effort is to bridge this very gap.

\section{Community well-being and indigenous communities of the NBR}

Eco-development initiatives to balance indigenous livelihoods and conservation objectives have been a primary focus of keystone foundation - an NGO engaged with indigenous communities of the NBR, for nearly two decades. Spanning across the states of Tamil Nadu, Kerala and Karnataka, the organization has been primarily working with the local particularly vulnerable tribal groups (PVTGs) communities that mainly include the Kurumbas, Irulas, Kotas, Todas, Cholanaickens, Kattunaickens and Paniyas.

The NBR (Figure 1), established in 1986 as part of the UNESCO Man and Biosphere initiative, harbours six PVTGs and over time, Keystone Foundation's activities have evolved into several broad thematic areas centred around eco-development. In 2015, through a process of reflection and deliberation, it was realized that focusing on 'development' through an economic/livelihoods lens alone was rather narrow; hence, a conscious decision was made to address indigenous issues more holistically, where the well-being of the community took centre stage.

\section{Community well-being and the 'invisible' subjectivities}

Indigenous communities are commonly subjected to two forms objectification: either through romanticization of their olden/exotic ways, or marginalization due to their 'powerlessness', thereby making them passive recipients of institutional interventions and turning them into 'victims of circumstance' in their own eyes. Archaic perceptions about indigenous lives often work detrimentally to their overall pursuits to well-being.

The narrowly perceived conceptions of both prosperity and 'poverty'; misplaced belief in the idea of conservation, excluding indigenous communities have severely compromised their well-being outcomes. In this regard, livelihood profiles are rapidly shifting to more dissociated ways of engaging with one's surroundings and those of the Irulas of the Nilgiris are, unfortunately, not an exception.

The identity (and well-being) of indigenous people are based significantly on the perception of their relations to their ecosystem ${ }^{11}$. It is also influenced by the social, cultural, economic and political world that intersect to form the basis of identity, the lack of which can negatively 


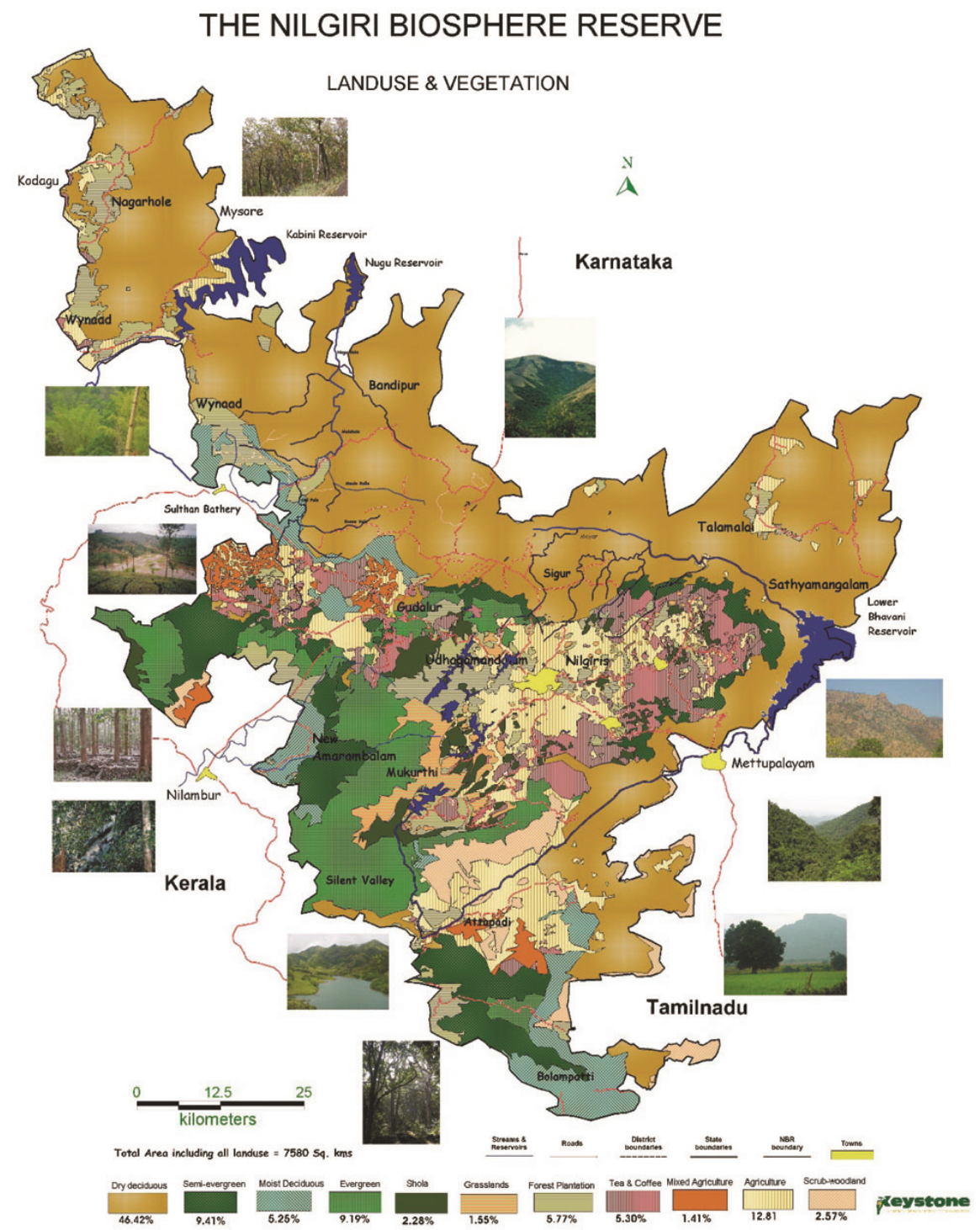

Figure 1. The Nilgiri Biosphere Reserve, Tamil Nadu, India (source: Keystone Foundation, Kotagiri, India).

impact their ability to maintain both their identity and well-being.

With this general understanding, in this article we discuss our efforts in assessing indigenous CWB, focusing on the Irula community of the NBR. Using the basic definition of community well-being by Wiseman and Brasher $^{5}$ as reference, we highlight the relevance of the well-being approach and the key indicators, to truly understand the life of the indigenous people, their preferences and priorities.

\section{Research methodology}

We identified six measurable components representing the four components of CWB (Table 1), also corresponding to the four programmatic components at
Keystone Foundation, and the corresponding measurable indicators.

These indicators were drawn from direct observations and interactions with the community members and practitioners working in the region for more than 26 years. The valid sample size consisted of 137 Irula individuals from 19 villages (20\% of household population), of the NBR (Aracode and Sigur). The data were collected from an adult member of the household using a paper-based survey. Here we present some insights from our preliminary results focusing on livelihood outcome as an integral component of well-being and its relationship with other well-being components, as well as key socio-demographic variables. We also draw from the existing literature and more than two decades of practice working with the Irulas, to discuss some of the unexpected associations and outcomes. 
Table 1. List of key components for assessing community well-being

\begin{tabular}{ll}
\hline Community well-being components & \multicolumn{1}{c}{ Measurable sub-components } \\
\hline Livelihood & Economic-security and food-security \\
Environmental-governance (socio-political security) & Land security; and Social security \\
Community health (physical conditions) and mental wellness and health & Mental health; and Physical health \\
Traditional-knowledge and culture (cultural identity and traditions) & Cultural identity and tradition \\
\hline
\end{tabular}

Table 2. Socio-demographic profile of the Irula respondents

\begin{tabular}{|c|c|c|c|c|c|}
\hline & Frequency & Valid percentage & & Frequency & Valid percentage \\
\hline Gender & & & Employment & & \\
\hline Male & 41 & 29.9 & Unemployed & 33 & 24.1 \\
\hline Female & 96 & 70.1 & Irregular & 77 & 56.2 \\
\hline \multirow[t]{4}{*}{ Total } & 137 & 100 & Seasonal & 24 & 17.5 \\
\hline & & & Regular & 2 & 1.5 \\
\hline & & & Permanent & 1 & 0.7 \\
\hline & & & Total & 137 & 100 \\
\hline Education & & & Income & & \\
\hline Illiteracy & 40 & 29.2 & $0-20,000$ & 8 & 5.8 \\
\hline Primary & 46 & 33.6 & $20,001-40,000$ & 9 & 6.6 \\
\hline Middle, and high school & 39 & 28.5 & $40,001-60,000$ & 22 & 16.1 \\
\hline Higher secondary & 11 & 8 & $60,001-80,000$ & 9 & 6.6 \\
\hline UG/diploma & 1 & 0.7 & $>80,001$ & 89 & 65 \\
\hline Total & 137 & 100 & Total & 137 & 100 \\
\hline
\end{tabular}

Table 3. Multiple regression results showing the key socio-demographic variables that have significant influence on each of the six community well-being (CWB) measurable components

\begin{tabular}{|c|c|c|c|c|c|c|}
\hline $\begin{array}{l}\text { Independent } \\
\text { variables/predictors }\end{array}$ & Livelihood & Land-security & Social-security & Physical health & Mental health & Cultural identity \\
\hline Socio-demographics & $\begin{array}{l}\text { Age*** }(-\mathrm{ve}) \\
\text { Gender* }^{(-\mathrm{ve})}\end{array}$ & $\begin{array}{c}\text { Educational } \\
\text { level** }(+\mathrm{ve})\end{array}$ & $\begin{array}{c}\text { Educational level** }(+\mathrm{ve}) \\
\text { Gender* }(+\mathrm{ve}) \\
\text { Age }^{*}(+\mathrm{ve})\end{array}$ & $\operatorname{Age}^{* *}(-\mathrm{ve})$ & $\begin{array}{c}\text { Age** }^{* *}(\mathrm{ve}) \\
\text { Gender* (+ve) } \\
\text { Income level* (+ve) }\end{array}$ & Age* (+ve) \\
\hline
\end{tabular}

$* P<0.1 ; * * P<0.05 ; * * * P<0.01$

\section{Results and discussion}

We used descriptive statistics to determine the sociodemographic profile of the respondents (Table 2). Linear regression was used to explore the nature of relationship between the six measurable CWB components with key socio-demographic indicators (Table 3) and the relationship between livelihood (the response variable) with key sociodemographic variables and other CWB components (Table 4). Assumptions of normality, absence of multicollinearity (correlation between variables less than 0.7 and variance inflation factor is less than 10) and homoscedasticity (using the Breusch-Pagan and Koenker test) were tested and met. We used SPSS vr.16 for all statistical analysis.

\section{Livelihood}

The Irula community has been a long-term recipient of state-sponsored schemes, and livelihood projects supported by local NGOs, including Keystone Founda- tion. Despite these efforts, the expected level of livelihood status has not been achieved in the community. This may be attributed to an inability to capture the actual needs of the community, or other factors evading our current field of vision. Nevertheless, our assessments indicate the positive impact of state social security schemes, such as old-age pensions on members of the tribal community (Table 4).

Livelihood security was found to decrease, significantly as age increased; so did the shift from men to women. Interestingly, physical health appeared to have a negative relationship with livelihood outcomes. This may pertain to increased susceptibility to substance abuse and alcoholism with improved income (livelihood), particularly among men.

Men, specifically the young, out-migrate for livelihood opportunities. Our observations suggests that in the case of the younger cohort, out-migration can be seen as a temporary exploration of mainstream lifestyle rather than the desire for a permanent shift, and the apparent upward mobility it offers. However, this 'exploratory 
out-migration' does come with a few negative implications. Lack of access to disposable income and support from family members creates stress and increased susceptibility to alcohol and substance-(ab)use. This, in turn, is shown to negatively impact physical health.

During seasons of out-migration, the onus of household responsibilities often falls on the women. Conflicted priorities may lead to either neglect of household responsibilities or of traditional livelihood practices, such as farming and collecting non-timber forest produce, etc. Such situations make it imperative to ensure livelihood security for both women and the older generation, especially since these sub-groups are the most vulnerable to changes in their life. In fact, studies report that livelihood security among tribal and rural women has positive impacts on household nutrition, education and children's health ${ }^{12-14}$.

\section{Environmental governance}

Formal governance systems are interspersed with informal mechanisms to present intriguing on-ground conditions $^{15}$. The implementation of the Forest Rights Act (FRA) 2006, offers a good example of this.

Access to land is the most basic condition to gain access to other resources, along with social security benefits, especially so, in the case of tribal communities. Lackadaisical implementation of the FRA, 2006, deferred until nearly a decade in Tamil Nadu, has violated the rights of the Irulas among other tribal groups in the NBR. In addition, social security status also has implications on the relationship between environmental governance and livelihoods of the Irulas (Table 4).

Sustained engagement in certain livelihood practices, health and cultural identity can promote overall wellbeing, which may further feed back into sustenance of community identity. This can only be achieved when land - the most basic resource - and other social entitlements are governable and accessible by those who know

Table 4. Regression analysis predicting effects of social-demographic and other CWB indicators on livelihood status among the Irulas

\begin{tabular}{llc}
\hline & \multicolumn{2}{c}{ Dependent variable } \\
\cline { 2 - 3 } & \multicolumn{2}{c}{ Livelihood } \\
\cline { 2 - 3 } Independent variables & \multicolumn{1}{c}{$\beta$} & Standard error \\
\hline Intercept & 4.605 & 0.606 \\
Age & $0.009^{* * *}(-\mathrm{ve})$ & 0.002 \\
Gender & $0.108^{*}(-\mathrm{ve})$ & 0.068 \\
Land security & 0.006 & 0.028 \\
Social security & $0.121^{* *}$ & 0.039 \\
Physical health & $0.274^{* *}(-\mathrm{ve})$ & 0.106 \\
Mental health & 0.051 & 0.064 \\
Cultural identity & 0.02 & 0.064 \\
Model $R^{2}$ & 0.205 & \\
\hline
\end{tabular}

$* P<0.1 ; * * P<0.05 ; * * * P<0.01$. it best. We found strong, positive associations between livelihood security and land security, and significant association between livelihood and social security. We argue that having land security and social security enhances autonomy to govern, and creates opportunities for decision-making. Autonomy to govern one's own land and resources can also ensure improved opportunities for sustained income and sustainable outcomes ${ }^{16}$. Despite having one of the most progressive Acts in place, the de facto conditions paint a rather contradictory picture. Increasing the awareness and capacity of indigenous communities to tread within the current legal landscape is something we believe to be an important ground-up step to demand otherwise dormant-lying rights.

\section{Traditional knowledge and culture}

Grossman ${ }^{17}$, quite intriguingly, sets out to capture 'culture' in the context of change and development. He stresses that

'... factors such as colonial policies, establishment of formal and informal relationships with government agencies and business interests ... and new forms of technology' end up altering 'previously established relationships among the natural environment, patterns of production, social organization, and cultural values with the local system'.

He forwards the view that wider and deeper immersion into the 'mainstream' economy by way of engaging in cash-cropping, can possibly have detrimental effects not only on the community and the autonomy and resilience of its members, but, by extension, may cause a disintegration of the very system that reinforces practice of culture. This theory begs our attention towards the erstwhile resilience capacity of indigenous communities such as those of the Nilgiris, which is now majorly known for its tea and coffee plantations than its traditional inhabitants. Viewing these indigenous communities as reservoirs of labour for estates that serve the interests of the few vested with power poses serious consequences for identity and its continuation among tribal communities.

Cultural identity is strong among communities who have the desire to express their identities through adherence to traditional and cultural norms and practices. When ethnic/cultural identities are strong and when they are recognized, accepted and supported, it contributes to well-being ${ }^{18}$.

We found a fairly high sense of cultural identity among the Irulas. This could perhaps be attributed to a sense of pride they hold over themselves and their practices. On the other hand, this could also be due to early interventions carried out to strengthen and support traditional knowledge and cultural practices preservation, especially 
with a focus on natural resource management among the communities. We also predict land security, good physical and mental health status having positive and significant influence on cultural identity. A strong self-perception and identification with the community feeds back into it through greater participation and engagement. Interestingly, gender did not have a significant or positive influence on cultural identity. One may be tempted to argue that this could be due to the specific gender roles assigned to women, which are often characterized by a largely 'domestic' way of engaging with the everyday, thus curtailing their movements, with far lesser avenues than men to assert/express their identity. However, based on our engagement with the Irulas, the previous argument appears clichéd. The presence of specific gender roles is strongly evident in our assessment. We argue that these strong gendered roles, in fact, render these communities with a strong cultural identity and often times, smaller the size of the community, stronger the cultural identity. On the other hand, age has a significant positive influence on cultural identity.

\section{Health and wellness}

To equate health indicators for indigenous and nonindigenous communities would not only be a gross mistake but willful ignorance of the contextually-rooted nature of lives of the indigenous community in general.

The alteration of balance and coexistence with the introduction of new governing rules has altered indigenous livelihood activities. Critiquing the contextually incongruent state welfare schemes, Ramakrishnan ${ }^{19}$ points to the role of the entity in hailing conservation backed by a systematic de-recognition of the indigenous ways, thereby having implications for forest landscapes and lives ${ }^{19}$.

Parallel to this, lack of livelihood opportunities in and around the villages often result in male out-migration, forcing them to settle for wage labour. Moving away from one's familiar surroundings and community can have negative implications on health, even if one's livelihood is secure. Moreover, a constant threat of displacement looming on forest-dwelling communities coupled with frequent human-wildlife conflicts nullify the benefits of having land security, thereby contributing to negative mental health. Yet, Peluso and Ribot ${ }^{20}$ stress upon access to land and ecosystems services and their associated benefits. Castree ${ }^{21}$ highlights the link between socio-ecological exclusion and how it may shape people's attitudes and perceptions, particularly if the process is conflict-ridden. People may feel mentally disassociated with their surroundings, thus affecting their interest in seeking benefits from the same and their contribution to wellness ${ }^{21}$. Increasing lifestyle changes from outmigration and exposure to mainstream cultures; liveli- hood opportunities; community cohesiveness, and interactions have all generally weakened, resulting in increased isolation and lack of support for the older and disabled community members. This manifests into poorer physical and mental health.

\section{Conclusion}

Our work in the NBR has informed us on how the everincreasing distance between the indigenous individual and his/her access to land and the nature of engaging with it have affected all other spheres of his/her life.

Being indigenous curtails free movement, both as an individual and as a community. Being indigenous, apparently, does not guarantee legitimate access to ancestral land. Being indigenous, also, does not render one 'expert' enough to manage the very forests he/she belongs to. However, being indigenous gives these communities services and support that maybe born out of concern for their existence and health, but mostly end up being incongruent to their felt needs and the landscape that taught them self-reliance. Lastly, being indigenous makes one arrive at a baseless conclusion that the forests are now the reason for their detriment, and vice versa. On the surface, much of this may appear true. However, a deeper search also reveals a side to indigeneity that is astute, where these communities recognize the value of their links to the forest land. This astuteness is utilized in ways that tend to benefit them. And this is where new paradigms of coexistence and indigeneity, institutions and processes of access, benefit-sharing and governance, and economics-all the basic foundations of ecodevelopment, also potentially converge.

It, indeed, is quite a disturbing colonial disposition to assume that indigenous lives, or even ours for that matter, are divorced from our ecosystem. The forest-based policies in India have continued to hold on to this idea of exclusivity in practice, despite decentralized provisions. Recent efforts by the National Biodiversity Mission attempt to bridge this long-standing void between the 'natural', and the 'social' spheres of life. The primary idea behind this mission on biodiversity and human wellbeing' is to bring to fore the undeniable link between biodiversity and its importance for well-being of those dependent on it. This stance takes a much-awaited departure from the archaic 'conservation of biodiversity by excluding humans' logic. Likewise, the nature of Keystone Foundation's work with indigenous communities has been more of a bottom-up engagement by gauging the needs on ground. This has enabled us to capture and understand the inter-linkages between well-being and the ecosystem of an individual, and thereby the community. Owing to our long-standing local engagement, we have been able to practice an iterative framework that we term as 'community well-being' - to view, assess and provide 
solutions to on-ground issues from a needs-based perspective, as well as addressing issues concerning a community more holistically. In the case of indigenous communities, individual well-being is an outcome of collective well-being. For collective well-being, social relationships, social cohesiveness, traditional ways of life rooted in the natural environment and cultural-identity, all become paramount.

Therefore, our effort has been to argue for contextually rooted solutions for issues starting from changes in governance practices causing changes in livelihood profiles to their repercussions for mental and physical health, traditional knowledge and culture, and the social fabric of the indigenous community as a whole.

1. Krishnan, A., The National Mission on Biodiversity and Human Well-Being: for a greener, healthier, and more sustainable way of life. National Centre for Biological Sciences (on-line), 3 March 2020; http://news.ncbs.res.in/bigger-picture/national-mission-biodiversity-and-human-well-being-greener-healthier-and-more

2. United Nations Development Programme (UNDP), India ranks 130 on 2018 Human Development Index. UNDP (on-line), 2018.

3. Comim, F., Beyond the HDI? Assessing alternative measures of human development from a capability perspective. UNDP, 2016.

4. Sen, A. K., Inequality Reexamined, Oxford University Press, 1992.

5. Wiseman, J. and Brasher, K., Community wellbeing in an unwell world: Trends, challenges, and possibilities. J. Publ. Health Policy, 2008, 29, 353-366.

6. Usher, P. J., Duhaime, G. and Searles, E., The household as an economic unit in arctic aboriginal communities and its measurement by means of a comprehensive survey. Soc. Indic. Res., 2003, 61, 175-202.

7. Kumaraswami, P., Culture, Identity, and Well-being, Palgrave Macmillan, New York, Social Life of Literature in Revolutionary Cuba, 2016, pp. 19-46

8. Hallett, D., Chandler, M. J. and Lalonde, C. E., Aboriginal language knowledge and youth suicide. Cogn. Dev., 2007, 22(3), 392-399.

9. Senecal, S. et al., Applying the community well-being index and the human development index to Inuit in Canada, 2008: 148.
10. Drawson, A. S., Mushquash, A. R. and Mushquash, C. J., First nations community well-being research and large data sets: a respectful caution. Int. J. Indigenous Health, 2017, 12(2), 15-24.

11. Wood, S. L. and DeClerck, F., Ecosystems and human wellbeing in the sustainable development goals. Front. Ecol. Environ., 2015, 13(3), 123.

12. Blumberg, R. L., Income under female versus male control: hypotheses from a theory of gender stratification and data from the Third World. J. Family Issues, 1988, 9(1), 51-84.

13. Duflo, E. and Udry, C., Intra-household resource allocation in Cote D'ivoire: social norms, separate accounts and consumption choices. National Bureau of Economic Research, Working Paper No. 10498, 2004.

14. Kennedy, E. and Peters, P., Household food security and child nutrition: the interaction of income and gender of household head. World Dev., 1992, 20(8), 1077-1085.

15. Weiss, T. G., Governance, good governance and global governance: conceptual and actual challenges. Third World Q., 2000, 21(5), 795-814.

16. Landesa, Land Rights (web); https://www.landesa.org/.

17. Grossman, L., The cultural ecology of economic development. Ann. Assoc. Am. Geogr., 1981, 71, 220-236.

18. Phinney, J. S. et al., Ethnic identity, immigration, and well-being: an interactional perspective. J. Soc. Sci., 2001, 57(3), 493-510.

19. Ramakrishnan, A., Rethinking Development and Environment in North Andaman. Econ. Polit. Wkly, 2019, 45-51.

20. Peluso, L. N. and Ribot, J., Postscript: a theory of access revisited. Soc. Nat. Resour., 2020, 33(2), 300-306.

21. Castree, N., The nature of produced nature: materiality and knowledge construction in Marxism. Antipode, 1995, 27(1), 12-48; doi:10.1111/j.1467-8330.1995.tb00260.

ACKNOWLEDGEMENTS. We thank the indigenous communities of the Nilgiri Biosphere Reserve for their support and cooperation participating in this study. We also thank our colleagues, Ms Snehlata Nath and Ms Pavitra Vasudevan for their inputs, and Ms Abhirami Murthy for help with editing. We thank the field volunteers and field staff for help during data collection.

Received 3 April 2020; revised accepted 26 March 2021

doi: $10.18520 / \mathrm{cs} / \mathrm{v} 121 / \mathrm{i} 1 / 37-43$ 